\title{
A análise funcionalista e o estabelecimento de quadros categoriais na gramática
}

The functionalist analysis and the establishment of categorical frameworks in grammar

\author{
Maria Helena de Moura Neves \\ Universidade Presbiteriana Mackenzie - UPM \\ Universidade Estadual Júlio de Mesquita Filho - UNESP
}

$\mathrm{CNPq}$

Resumo

$\mathrm{O}$ estudo, comprometido com uma visão funcionalista da gramática, toma como objeto de análise as classes de palavras, buscando mostrar que a rigidez categorial não se sustenta no uso linguístico. A amostra de análise apresentada parte das soluçóes dos dicionários no registro das classes de palavras, especialmente nos casos de fluidez categorial manifestada no uso. Tomam-se como evidências aspectos da gramaticalização em português, defendendo que a organização gramatical da língua dispõe de propriedades que sustentam os processos de deslizamento categorial, por mais singulares que possam parecer ao exame.

Palavras-chave

Funcionalismo, Fluidez categorial, Gramaticalização. 


\section{Abstract}

Committed to a functionalist view of grammar, this study takes word classes as its object of analysis, aiming to show that categorical rigidity cannot be upheld in linguistic use. The analysis sample presented starts from the solutions of dictionaries in the registration of word classes parts and from the fluidity that these classes show in their use. Aspects of grammaticalization in Portuguese language are taken as evidence. It is argued that the grammatical organization of language has properties that support categorical shift processes, however singular they may seem to examination.

\section{Keywords}

Functionalism, Categorical fluidity, Grammaticalization. 


\section{Introdução}

Saí menino de minha terra.

Manuel Bandeira

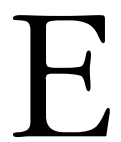

ste texto busca dar uma amostra da conveniência teórica e prática de uma análise funcional da linguagem e das línguas. A análise se assenta no mais amplo contexto em que as propostas funcionalistas têm-se manifestado (conforme explicitado em NEVES, 2011c), ou seja, ela não se filia rigidamente a nenhuma corrente teórica funcionalista particular, apenas se vincula à proposta geral de contemplar os usos linguísticos, para o exame da funcionalidade da linguagem.

O centro de observação são as entidades que mais facilmente se prenderiam a uma visão estanque da língua, as classes de palavras, que foram o ponto de partida na consideração das categorias de linguagem, desde muito antes da instalação de uma ciência linguística no pensamento ocidental. A partir daí, o que se propóe é exatamente abandonar a facilidade dessa zona de conforto que é a pregação não sustentada de uma autonomia a toda prova dos quadros categoriais, esses que vêm passando prontos pelas geraçôes, e aí estão diante de nós, como se legitimamente existissem apenas como pré-construtos que devem ser observados e aceitos sem reflexão. ${ }^{1}$

A proposta já implica a admissão de uma relação entre, de um lado, a ciência e a arte da gramática, e, de outro, o processo interveniente de gramaticalização. ${ }^{2}$ Para encaminhamento de análise, a proposta se apoia na ciência e na arte da lexicografia, que é justamente o mais natural e o mais previsto campo de fixação e de registro das classes de palavras.

\section{A proposta}

Na base, estas reflexões vão ligar gramática e gramaticalização por uma via extremamente reveladora do funcionamento linguístico, sob qualquer aspecto que se queira considerá-lo. Especificamente, aqui, assenta-se a via da fluidez 
categorial, e, por essa mesma via, a da indeterminação da linguagem. E vamos observar o que nos elucida a lexicografia.

Tenho insistido na dificuldade e no perigo de estabelecimento de fronteiras rígidas quando se trata de categorias de linguagem e de línguas naturais. ${ }^{3}$ Isso não vale apenas para um estudo que se defina como de estabelecimento das próprias categorias e de sua natureza, mas extrapola esse campo para chegar a responder sobre um sem-número de considerações que se façam na observação direta do funcionamento da linguagem.

Esse ponto de partida - já assentado sobre a assunção de uma imprecisão de limites entre categorias - condiciona uma visão de gramaticalização que prescinde de justificativas para defender a naturalidade desse processo, essencial na compreensão de variação e mudança linguísticas. Por tal visão, verificar um ou outro percurso de gramaticalização deixa de ser um trabalho pontual de observação de casos particulares e passa a ser um trabalho em que o particular é nada mais do que comprobatório de tendências gerais que governam o funcionamento da linguagem, e que, naturalmente, dele se esperam. E isso vale para o campo mais significativo do funcionamento da linguagem, aquele que liga classes e funções, e, por aí, liga as "categorias" à "interpretação" - para tomar emprestada a fundamental proposta de Aristóteles, que, obviamente, à época, se situava no campo da lógica, entretanto sempre abstraída da linguagem (NEVES, 2005). Amplificando a "interpretação" de Aristóteles (1963) - ou seja, entrando propriamente na gramática - andemos por essa via.

\section{As tendências}

Perguntadas sobre quais as classes de palavras de partida na consideração das categorias de linguagem, as pessoas se dividirão entre verbo e substantivo, exatamente as duas primeiras categorias que o pensamento gramatical ocidental distinguiu, nomeou e classificou. Foi com essas duas categorias que Platão equacionou a próte symploké (a primeira e mais básica combinação na linguagem), ou seja, aquela "articulação dos termos", encaminhando para a infinitude, na geração das combinações, no mais incrível prenúncio de uma teoria propriamente linguística (NEVES, 2005). Está aí, pois, tanto do ponto de vista da lógica, com a sua busca da verdade, como do ponto de vista do outro extremo, que é o da pragmática com a sua busca de adequação, a articulação básica da 
proposição, exatamente o "falar de e dizer que". Ora, não há um "falar de" sem algo que um substantivo nomeie, e não há um "dizer que” sem um predicado - e, por aí, um verbo, mesmo que seja um verbo apenas funcional, como o de ligação - que constitua exatamente aquilo que é "enunciado". Tal é, na base, o esqueleto sistêmico do acionamento da linguagem.

Mas, qual das duas categorias é a mais estável, sustentada, autônoma, lexical? Não vou entrar em discussões filosóficas, mas o trato comum com a linguagem já nos diz que é muito mais difícil entendermos ser possível "falar de" uma entidade sem "dizer que", ou seja, falar de algo sem nada dizer, do que o contrário. Grosseiramente, pode ser afirmado que haveria uma proposição em chove, mas não em (a) nuvem ou em (a) água. Estou sendo até banal nestas considerações, mas com certeza algo diz a quem, numa língua natural, usa a palavra que, no acionamento da linguagem, o verbo é uma categoria singular, é inassimilável. Não à toa que "no princípio era o verbo"...

Com esse inassimilável, volto à questão da fluidez categorial, e no caminho da gramaticalização, volto ao substantivo.

\section{As categorias}

Agora, já irei pela via dos dicionários.

\subsection{O substantivo}

Comecemos, pois, pelo substantivo, que, em termos de autonomia lexical - já deixado de lado o verbo - seria a primeira classe de palavras a considerar. É nela que entra em questão a discussão sobre o caráter natural ou arbitrário (lembro as liçôes de Saussure), ou convencional (lembro as lições de Aristóteles) da denominação. Platão já havia discutido a controvérsia filosófica entre naturalismo e convencionalismo, sem se decidir por nenhuma das soluções, o que ocorria, aliás, porque Platão buscava aporias, não soluçōes, e por isso mesmo tratava as questóes supostamente decisórias por meio de diálogos, não de textos de autoria, e, portanto, não de dogmas (NEVES, 2005). Aristóteles, por sua vez, também por via da lógica, já nos deixou, explicitamente, a categoria nome definida como "convencional" (katà synthéken). Ou seja: entre o "conceito, o nome e a coisa", há sempre correspondência, mas não necessariamente congruência; o nome revela a relação conceitual, e, por meio dela, revela a ousía, a "coisa", mas entre a coisa e o 
nome não há relação de semelhança, e não há, pois, uma relação "natural" (NEVES, 2005). Por isso mesmo, os nomes não são os mesmos para todos os homens, já era o argumento. Assim, a significação é algo que resulta de acordo e convenção, obviamente não uma convenção individual e consentida.

E agora entro na sustentação lexicográfica para o exame que faço. Ora, em que se assenta essa convencionalidade?

Quem busca um dicionário busca significados. Em termos lexicográficos, o que vem registrado é o que se tem denominado como acepção de cada entrada, que, em princípio, é traduzida em uma definição lexicográfica, muito semelhante ao modelo da definição aristotélica: ou seja, gênero + diferenciação específica, algo como o que está na abertura do verbete homem no Aurélio e no Houaiss, ${ }^{4}$ respectivamente, e que transcrevo adiante. Trata-se de apenas uma amostra, que é a acepção 1 de cada um desses dois dicionários. ${ }^{5}$

homem S.m. 1. Qualquer indivíduo pertencente à espécie animal que apresenta o maior grau de complexidade na escala evolutiva; ser humano (FERREIRA, 1999).

homem S.m. 1. Rubrica: biologia. mamífero da ordem dos primatas, único representante vivente do gên. Homo, da espécie Homo sapiens, caracterizado por ter cérebro volumoso, posição ereta, mãos preênseis, inteligência dotada da faculdade de abstração e generalização, e capacidade para produzir linguagem articulada (HOUAISS, 2001).

Facilmente se verifica, pois, que, na definição lexicográfica, o significado de um substantivo consiste na indicação de um conjunto de propriedades, postas em hierarquização; ou seja: parte-se da indicação do gênero a que a coisa nomeada pertence e vai-se à indicação das diferenciações específicas (espécies), que possam chegar a definir aquilo que a palavra significa. ${ }^{6}$ Por mais que o dicionário estenda esse oferecimento de diferenciação específica, dificilmente ele alcançará univocidade, a não ser em definições científicas, fato que, obviamente, não será tratado aqui:

a) No caso do substantivo homem, há mais de um campo em que se poderá buscar chegar à univocidade, ou exatidão, da definição, e até se conseguirá, por exemplo, em um campo como o da Biologia, que é o invocado pelo Houaiss, no oferecimento da acepção 1, na qual ressalta o adjetivo único. 
b) Cabe ver, por outro lado, que a definição do Aurélio prefere manter uma indicação ligada a grau, portanto menos pontual, menos unívoca, o que é perfeitamente aceitável - e até inevitável - na lexicografia. ${ }^{7}$

\subsection{Do substantivo ao adjetivo}

Ora, caminhemos daí, ou seja, de definições, especificamente redigidas em dicionários como tais, para deslizamentos categoriais que possam representar encaminhamentos na direção de gramaticalização. Trata-se de algo que não apenas representa desvios de significado, mas, mais que isso, algo que implica - digamos assim - uma desistência de que a definição oferecida se aplique apenas a substantivos. Lembre-se que nosso campo de exame são classes, categorias, e, em nome da ciência, esses encaminhamentos terão de ser discutidos e apresentados dentro das constantes pelas quais as classes envolvidas têm a sua natureza caracterizada. Ou seja, como bem marcou Coseriu (1967), cada termo tem, sustentando a sua definição específica, uma definição categorial. Para isso tomo mais três acepções de homem que se oferecem entre as 16 existentes no Houaiss. Obviamente, são casos em que já não há sinonímia com "ser humano", mas mantém-se a indicação da categoria substantivo. ${ }^{8}$

- 4 indivíduo do sexo masculino

- 5 homem (acp. 4) que já atingiu a idade adulta; homem-feito

A partir dessas indicações, é de concluir que, para a acepção 7, pode ser composta esta definição lexicográfica:

homem 7 indivíduo do sexo masculino (acp. 4)

- que já atingiu a idade adulta (acp.5)

- em que sobressaem qualidades como coragem, força, determinação, vigor sexual.

Assim, à acepção 4 (já um conjunto de propriedades ancoradas em uma entidade nomeada: indivíduo) só se acrescenta uma série de aportes "adjetivos": há sucessivas atribuições de propriedades.

Essa característica de atuar atribuindo propriedades é o que se vê claramente nestes usos de palavras, que, em princípio, são catalogadas como substantivos: 
(1) Esse padre é muito homem. Vir no meio dum fogo desse! (GCC) ${ }^{10}$

(2) E olhe que aquilo é muito mulher. (GA)

(3) Ela é muito gente fina, e muito trabalhadora pelo que eu vi lá, tá ligado? (CP)

Veja-se que, propositadamente, começo o exame das ocorrências de homem, como atribuidor de propriedade, escolhendo a posição predicativa - no caso, predicativo do sujeito com verbo de ligação -, o que escancara uma função atributiva, ou atribuidora, exatamente a função à qual o adjetivo está particularmente votado. Na verdade, essa é a sua definição categorial. ${ }^{11}$ Também escancara essa função o fato de que, em (3), a expressão substantiva gente fina vem coordenada com o adjetivo trabalhadora.

Continuando, vejam-se os substantivos destacados em:

(4) Não podia saber se o dinheiro vinha de uma conta fantasma. (VEJ)

(5) Antigamente, o nome gafieira não era associado à ideia de ambiente perigoso, pouco família. (REA)

(6) Pior é que nós, jornalistas, temos que entender e atingir o público alvo. (RI)

Em (4), trata-se da límpida e pura colocação de um substantivo (fantasma) à direita de outro (conta), posição que, no sistema do português pertence ao significado categorial ${ }^{12}$ do modificador nominal, ou seja, ao significado categorial do adjetivo (lembrando-se que nossos adjetivos, quando usados não marcadamente, se colocam à direita do substantivo, diferentemente do inglês, por exemplo). A partir daí, o que se vê é que fantasma atribui determinada(s) propriedade(s) a uma conta.

Em (5), mantém-se essa mesma situação de um substantivo (família) colocar-se à direita de outro (ambiente), e com uma especificidade ainda maior, pois esse segundo substantivo (em posição de adjetivo) vem intensificado por um advérbio (pouco).

Em (6), trata-se dessa mesma situação de um substantivo (alvo) colocarse à direita de outro (público), embora não haja nenhuma qualidade, propriamente, em jogo. Ou seja, alvo não é uma qualidade atribuída a público, tanto que não se poderia dizer "público muito / pouco alvo". Isso, entretanto, não toca o cerne 
da condição que define (abstratamente) a categoria adjetivo, isto é, alvo não deixa, por isso, de estar encaminhando-se para uma condição adjetiva.

E por aí vamos verificar melhor as condiçōes pelas quais nossa gramática rege esse tipo de deslizamento, que constitui uma das situações em que se configura o fato que vem sendo chamado de gramaticalização.

No trato tradicional ocidental com a metalinguística, vem-se indicando que o substantivo é um nome. O que às vezes não temos entendido muito bem é de quê, exatamente, cada substantivo é nome. ${ }^{13}$

Voltemos ao dicionário, que é exatamente o repositório que nos pode guiar na visão de significados potenciais para as palavras da língua, ou seja, na visão das matrizes de propriedades (pelo gênero e pelas diferenciaçōes específicas) que configuram a contraparte significativa potencial de cada nome / cada substantivo da língua. Ou seja, o que o substantivo nomeia é um conjunto de propriedades, conjunto que se atualiza e se configura funcionalmente a cada uso, a partir daquela "receita" de potencialidades que os dicionários nos dão. Ora, homem é o nome pelo qual um falante do português se refere a qualquer indivíduo daquela classe que se configura por aquele determinado conjunto de propriedades significado naquela determinada instância. Volto, então, a um ponto que ressaltei: muito raramente se chega a explicitar uma indicação completa, absoluta de tal conjunto, e raramente se chega a uma definição exaustiva.

Ora, e o que é que um substantivo que venha à direita de outro mantém dessa configuraçãa? Vejamos homem e mulher nestas ocorrências:

(7) Trata-se de fazer entrar a parte mulher dos seres falantes, que podem permanecer, do lado homem, mantendo o rechaço ao feminino. ${ }^{14}$

(8) "Queria dar uma virada na minha carreira, mostrar o meu lado mulher", resume Patrícia Luchesi sobre as fotos que fez. (FSP)

Quanto à expressão do conjunto das propriedades nomeado em mulher (e em homem nessas frases, com certeza elas se mantêm para acoplar-se ao que está referenciado (e nomeado) pelo substantivo da esquerda: parte mulher, lado homem, lado mulher.

Ora, o substantivo é nome exatamente por via da sua referencialidade, ligada à conceptualização. Ou seja, seu estatuto envolve que ele "referencia": é por via de uma nomeação de referente que ele pode carregar em si a configuração conceptual (global) da entidade "homem" na configuração linguística (linear) 
da palavra homem. É isso que não ocorre quando a palavra homem está na configuração lado homem. Aquele conjunto de propriedades que estão nomeadas - no caso dessa determinada acepção -, esse se mantém e é levado para o substantivo da esquerda, mas como modificação adnominal.

Do mesmo modo, também é o conjunto de propriedades nomeadas que é levado para cada núcleo do sujeito nos casos de "Esse padre é muito homem" e de "Saí menino da minha terra".

Assim, claramente há um elemento implicado no jogo das diferenciações que comecei a trabalhar a partir de aproximaçōes: substantivo e adjetivo fazem aporte de propriedades, mas só como substantivo o conjunto tem referencialidade, e isso é, pois, o que distingue categorialmente um do outro, na prototipia. Isso significa que não tomo como mecanismo de decisão sistêmica para a validação categorial, em cada situação de ocorrência, o valor semântico em si, porque esse é efeito, e é exatamente o efeito buscado, no uso, com o deslizamento. Mas não é processo básico. ${ }^{15}$

Ora, a referencialidade, componente essencial da definição categorial do substantivo, constitui uma saída para outro mundo que não o das relações puramente abstratas da gramática, o que faz bem entender por que homem é substantivo nestas frases: ${ }^{16}$

(9) Vejam como este homem é mau! (MCR)

- em que homem é um objeto de discurso, e faz referenciação situacional ou textual, e definida, identificável.

(10) E foi um dia, um homem enfermou. (CIG)

- em que homem é objeto de discurso, e faz referenciação situacional ou textual, mesmo que indefinida, não identificável.

(11) Joaquim Antonio de Amorim precisa de um homem que tenha mais de quarenta anos. (VOL)

- em que homem nem chega a ser objeto de discurso: ele não insere um referente no texto, não faz referenciação situacional ou textual.

Registre-se que nenhuma dessas diferenças que apontei atinge nem a propriedade substantiva que homem tem, nesses três casos, de constituir a contraparte linguística de um referente conceptual, nem a propriedade não necessariamente substantiva - a isso ligada - que homem tem de englobar um 
feixe de propriedades. É por aí que homem pode despegar-se da propriedade substantiva (mais lexical, menos gramatical) e conservar apenas a propriedade não substantiva, e sim atributiva (obviamente mais gramatical), de indicar propriedade(s), sem constituir uma denominação de referente, como em conta fantasma, etc. Eis por que, no caminho de uma gramaticalização, um substantivo desliza facilmente para a categoria adjetiva, bastando, para isso, que uma de suas propriedades se despegue do conjunto. Veja-se a ilustração disso nesta frase:

(12) Só agora é que Fischer conhecia o gênero de homem que florescera no selo cruel desses campos e via quão pouco homem ele era, na realidade. (SVI)

\subsection{Do adjetivo ao advérbio}

E daí, então, para onde iremos, se quisermos continuar na mesma direção, em busca de novos deslizamentos que, regendo-se pelos mesmos princípios, representem o enfraquecimento de algum traço de definição menos gramatical, e o consequente reforço de algum traço de definição mais gramatical? Então, partindo, agora, do adjetivo, para onde iremos, e por que via?

Já vimos que o estatuto categorial do adjetivo se define por uma função atributiva de propriedade(s), que é uma função modificadora - repito -, como a do substantivo, ou seja, que não é contraparte de alguma entidade conceptual, que é o caso do substantivo. Ora, isso implica que é necessário ir mais além na configuração do estatuto categorial do adjetivo, porque, se ele é atributivo / modificador, há a definir qual a categoria - ou categorias - da palavra em que incidem tais atribuiçôes. Vimos que o adjetivo faz atribuição de propriedades exatamente a substantivos, que, em geral estarão à sua esquerda, no caso de atribuição adnominal, nucleando os sintagmas denominados, exatamente, como nominais ${ }^{17}(\mathrm{SNs})$, ou estarão como predicativo, função ainda mais evidentemente atribuidora.

Ora, um novo deslizamento categorial vai surgir por essa direção. É absolutamente comum a atribuição das propriedades adjetivas a núcleos substantivos, como nestes casos:

a) adnominalmente, como em 
(13) Jogo duro, aquele. Ficamos pela sete. (AGO)

(14) Claro que ninguém poderia esperar jogo limpo da parte de um sujeito como Mr. Scratch. (MNA)

b) predicativamente, como em

(15) Vai pensando que o jogo é limpo, mas está vendido. (FSP)

(16) Moas reconheceu que o jogo foi duro e que o Uruguai foi até violento em certos momentos. (FSP)

E é por aí que se vai do adjetivo ao advérbio, sempre em um contínuo.

Deve-se lembrar que a função de um advérbio de modo é exatamente predicativa, em relação ao núcleo da predicação, ou seja, é modificadora, é qualificadora, tanto quanto a do adjetivo do tipo qualificador, mudando apenas o âmbito de incidência, que deixa de ser um núcleo substantivo. ${ }^{18}$

(17) Jogava limpo, com classe. Foi dono de um belo futebol. (DIN)

(18) Percebi que deveria começar a jogar duro se quisesse continuar com saúde e trabalhando naquele assunto. (RI)

(19) Eu quero agir direito, quero me adaptar e ponho tudo a perder. (I)

(20) Canta rouco, gosta muito de música pop. (FSP)

\section{A generalização da proposta}

Eu poderia continuar na busca de constantes caracterizadoras (ou, mesmo, definitórias) do processo, mas só vou dar uma amostra que considero elucidadora, porque exatamente de uma classe nascente na gramática de nossa língua, a das chamadas - de modo muito interessante - preposiçóes acidentais. $\mathrm{Na}$ pouca precisão e pouca estabilidade categorial que os caracteriza, esses elementos podem dar-nos um verdadeiro mapa de regularidades (para generalizaçôes) no processo de encaminhamento de estatutos menos gramaticais para estatutos mais gramaticais, que é exatamente o fato da gramaticalização, no sistema "gramática" da língua. Essas palavras vêm de particípios, advérbios, ou mesmo de conjunçóes que já vieram de particípios. ${ }^{19}$ 
Em estudo que realizei (publicado na Revista $A L F A L$, v. 23, 2010b), tomei doze preposições desse tipo e fui observar o modo como quatro dicionários contemporâneos as categorizam, nas entradas. Este foi o quadro:

\section{QUADRO 1}

Categorização gramatical das chamadas "preposições acidentais"

\begin{tabular}{|l|c|c|c|c|c|c|c|c|}
\hline \multirow{2}{*}{ verbetes } & \multicolumn{2}{|c|}{ Houaiss } & \multicolumn{2}{c|}{ Aurélio } & \multicolumn{2}{c|}{ DUP } & \multicolumn{2}{c|}{ Dic. Unesp } \\
\cline { 2 - 10 } & $\mathrm{Adv}$ & Prep & $\mathrm{Adv}$ & Prep & $\mathrm{Adv}$ & Prep & Adv & Prep \\
\hline afora & $\mathrm{x}$ & $\mathrm{x}$ & $\mathrm{x}$ & $\mathrm{x}$ & $\mathrm{x}$ & $\mathrm{x}$ & $\mathrm{x}$ & $\mathrm{x}$ \\
\hline como & $\mathrm{x}$ & & $\mathrm{x}$ & & $\mathrm{x}$ & $\mathrm{x}$ & $\mathrm{x}$ & $\mathrm{x}$ \\
\hline conforme & & $\mathrm{x}$ & $\mathrm{x}$ & & & $\mathrm{x}$ & & $\mathrm{x}$ \\
\hline consoante & & $\mathrm{x}$ & & $\mathrm{x}$ & & $\mathrm{x}$ & & $\mathrm{x}$ \\
\hline exceto & & $\mathrm{x}$ & & $\mathrm{x}$ & & $\mathrm{x}$ & & $\mathrm{x}$ \\
\hline exclusive & $\mathrm{x}$ & $\mathrm{x}$ & $\mathrm{x}$ & & $\mathrm{x}$ & & - & - \\
\hline fora & $\mathrm{x}$ & $\mathrm{x}$ & $\mathrm{x}$ & $\mathrm{x}$ & $\mathrm{x}$ & $\mathrm{x}$ & $\mathrm{x}$ & $\mathrm{x}$ \\
\hline inclusive & $\mathrm{x}$ & $\mathrm{x}$ & $\mathrm{x}$ & & $\mathrm{x}$ & & $\mathrm{x}$ & $\mathrm{x}$ \\
\hline não obstante & $\mathrm{x}$ & $\mathrm{x}$ & $\mathrm{x}$ & $\mathrm{x}$ & $\mathrm{x}$ & $\mathrm{x}$ & $\mathrm{x}$ & $\mathrm{x}$ \\
\hline salvo & & $\mathrm{x}$ & & $\mathrm{x}$ & & $\mathrm{x}$ & & $\mathrm{x}$ \\
\hline senão & & $\mathrm{x}$ & & $\mathrm{x}$ & & $\mathrm{x}$ & & \\
\hline visto & & $\mathrm{x}$ & & & $\mathrm{x}$ & & & \\
\hline
\end{tabular}

Fonte: Elaboração própria.

Várias observações gerais foram feitas nesse trabalho, e aqui vêm algumas poucas:

a) apenas dois desses elementos são colocados, em todos os dicionários, nas duas categorias (preposição e advérbio): afora e não obstante;

b) apenas seis elementos (50\%) são categorizados em todos os dicionários como preposição, e, por outro lado, apenas cinco desses elementos são categorizados em todos os dicionários como advérbio;

c) entretanto, nenhum dos doze elementos deixa de ser categorizado, em pelo menos um dicionário, como preposição.

Buscando constantes, verifiquei que a natureza participial de base de alguns desses elementos os encaminha para uma gramaticalização na direção 
prepositiva, não adverbial: consoante, exceto e salvo estão presentes como preposição em todos os dicionários. Entretanto, a natureza participial de outros deles deixa aberta uma direção adverbial da gramaticalização (ao lado da direção prepositiva), dada a estrutura argumental do verbo de base; por exemplo, vejase que o elemento não obstante está presente como preposição e como advérbio em todos os dicionários. Verifiquei ainda que a natureza já adverbial de outros (fora e afora, além de senão) também encaminha para uma gramaticalização na direção prepositiva, que é de relações mais abstratas do que as do advérbio: de fato, fora e afora, como circunstanciais valenciais de base que são - acionadores de uma estrutura argumental, com implicação de um complemento, portanto, com algum componente de classes mais lexicais, valenciais, predicadoras -, facilmente passam a um uso juntivo, bem próprio de preposição: esses dois elementos são categorizados como preposição em todos os seis dicionários, aliás, até nos mais antigos (Aulete e Melhoramentos).

\section{Considerações finais}

$\mathrm{Na}$ amostra de análise apresentada, altamente comprometida com uma visão funcionalista da gramática, pretendi, defender a necessidade da relativização de fronteiras categoriais no estudo da linguagem, tomando como evidência aspectos da gramaticalização em português, revelados no uso, e, acima de tudo, mostrando que há propriedades da organização gramatical da língua que sustentam todos os processos, por mais singulares ou individualizados que possam parecer ao exame.

$\mathrm{O}$ foco nos deslizamentos assenta-se naquilo que considero uma noção crucial, a de que as entidades linguísticas se configuram com zonas difusas na significação, com superposições funcionais e com imprecisão de fronteiras categoriais, o que - exatamente - tem de estar na base da consideração do que seja o sistema linguístico em cada momento de sua (re)organização. Essa é uma visão que contempla a linguagem em uso como chave e como testemunho do funcionamento de uma língua natural, a qual, de um lado, é patrimônio de inserção histórica e social, instável e mutável, mas, de outro lado, se rege por constantes que sustentam o sistema, o qual nunca foge ao equilíbrio. 


\section{Notas}

${ }^{1}$ A questão da categorização é vista segundo obras consagradas sobre o tema, (entre outras: JACKENDOFF, R., 1983a e 1983b; LABOV, W., 1973; LAKOFF, G., 1987; LANGACKER, R. W., 1987; ROSCH, E., 1978; ROSCH, E.; LLOYD, B. B. (Ed.), 1978; TAYLOR, J., 1995).

${ }^{2}$ Entenda-se o termo gramaticalização a partir de obras continuamente referidas nos estudos sobre o tema (entre outras, HEINE, B.; CLAUDI, U.; HÜNNEMEYER, F., 1991; HOPPER, P.; TRAUGOTT, E.C., 2003; TRAUGOTT, E. C.; HEINE, B. (Ed.), 1991; WISHER, I. (Ed.), 2002) e de obras em que eu própria tenho trabalhado o tema (entre outras: Neves, M. H. M. 2010a; 2010b; 2010c; 2011b; 2012).

${ }^{3}$ Neves, M.H.M. 2008; 2010a; 2010b; 2011b; 2012; no prelo; entre outros.

${ }^{4}$ Evito dar exemplos dos dicionários de autoria da equipe a que pertenço (BORBA (Org.), 1997, 2002, 2005 e no prelo), porque a indicação poderia ser considerada viciada, já comprometida com minhas propostas.

${ }^{5}$ Em parêntese, indique-se que o Aurélio tem 14 acepções para o verbete, e o Houaiss tem 16 .

${ }^{6}$ Marquei essas duas indicações de espécie com negrito, na cópia da definição dos dois dicionários que foi transcrita: são indivíduo e mamífero, respectivamente.

${ }^{7}$ Por simples curiosidade, lembro: $1^{\circ}$, quanto ao Houaiss, a definição propriamente dita (que só chega à univocidade porque é tratada pela ciência, no campo da Biologia) termina em Homo sapiens; tudo o que vem a seguir ("caracterizado por ter cérebro volumoso, posição ereta, mãos preênseis, inteligência dotada da faculdade de abstração e generalização, e capacidade para produzir linguagem articulada") são informações acrescidas, qualificadoras; $2^{\circ}$, quanto ao Aurélio, a univocidade foi atingida pela sinonímia ("ser humano"), não pela definição, o que é muito difícil ocorrer.

${ }^{8}$ Atente-se para a marcação que faço em negrito, no verbete. Observe-se que, neste momento, já nos preparamos para ir do substantivo ao adjetivo.

${ }^{9}$ A abreviatura de acepção adotada no Houaiss é essa: acp.

${ }^{10}$ As ocorrências que neste texto se apresentam (todas de linguagem escrita) foram retiradas do banco de dados do Laboratório de Estudos Lexicográficos da Faculdade de Ciências e Letras da UNESP, Câmpus de Araraquara, o mesmo que serviu à elaboração da Gramática de usos do português (NEVES, 2011a), do Dicionário de usos do português do Brasil (BORBA, coord. 2002) e do Guia de uso do português. Confrontando regras e usos (NEVES, 2003). 
${ }^{11}$ É interessante separar, já no ponto de partida, os predicativos, porque, nesse caso, é a construção que opera a mudança de classe: um predicativo tem um contexto sintático definidor dentro do predicado, enquanto uma simples colocação à direita não constitui uma sintaxe definidora para a categoria adjetivo, porque é possível haver adjetivo à esquerda do substantivo. Compare-se este caso com o caso (de direção inversa) da substantivação do adjetivo (ver as notas 16 e 19), em que não se configura, exatamente, um "deslizamento" categorial.

${ }^{12}$ Lembro novamente Coseriu (1967).

${ }^{13}$ Cabe observar que tradicionalmente se vem tratando muito mal a diferenciação entre substantivo próprio e substantivo comum, o que não cabe discutir aqui.

${ }^{14}$ Essa frase não é retirada do córpus de análise indicado. Ela é retirada do texto "Para o homem, o amor; para uma mulher, o dizer", da autoria de Isabel Martins, apresentado no IV Congreso Internacional de Convergencia la Experiencia del Psicoanálisis. Lo sexual: inhibición, cuerpo, sintoma, realizado no período de 8, 9 e 10 de maio de 2009 em Buenos Aires, Argentina. Disponível em: <www.convergenciafreudlacan.org/ .../Martins-Considera-Isabel-Por-pdf-585.pdf >. Acesso em: 21 jan. 2012.

${ }^{15}$ Veja-se este exemplo: Mas se conta fantasma não existe, como é que pode ser vendida? (FSP). Dá para conferir, por aí, o estatuto "substantivo" de conta: esse "existe" (seja em qualquer mundo) reflete a referencialidade do substantivo.

${ }^{16} \mathrm{Um}$ elemento que ilustra o caso de um adjetivo adquirir essa propriedade substantiva (de correspondência a um referente conceptual) é o adjetivo substantivado, como em o pobre ou um rico. Observe-se que já não se trata, aí (nesse movimento inverso, que vai do mais gramatical para o mais lexical), de deslizamento categorial: trata-se de um processo particular de derivação imprópria, que se faz por procedimentos específicos da construção do enunciado.

${ }^{17}$ Não se esqueça o fato de que, na história das ideias gramaticais no Ocidente, a própria denominação da classe advérbio (cujo membro prototípico é o advérbio de modo) é correlata à denominação adjetivo: o advérbio seria o adjetivo do verbo.

${ }^{18} \mathrm{O}$ SN remete a um referente nomeando-o segundo um determinado feixe de propriedades. Aí se está no território da gramática do texto, porque a referencialidade textual não é referencialidade para um mundo que não o da gramática. Esta última qualidade referencial é a do substantivo, ela é categorial, não funcional (sintagmática).

${ }^{19}$ De conjunção vai a preposição, mas, de preposição para ir a conjunção, só com o complementizador. Ou seja: só com o elemento mais "gramatical" de todos se faz a mudança de uma classe mais gramatical para uma menos gramatical. Esse caso pode ser comparado com o da substantivação, provando-se mais uma vez, que, 
quando a direção é invertida (de menos lexical para mais lexical), não se trata de simples deslizamento, mas existe um processo interferente na alteração categorial. A unidirecionalidade da gramaticalização, aliás, é um corolário desse fato.

\section{Referências}

ARISTOTLE. Categories and De interpretation. Translated by J. L. Ackrill. Oxford: Clarendon Press, 1963.

BANDEIRA, M. Estrela da vida inteira. In: Poesias Reunidas. Rio de Janeiro: José Olympio, 1966. p. 196.

BORBA, Francisco da Silva (Coord.). Dicionário gramatical de verbos do português contemporâneo do Brasil. 2. ed. 1 reimpressão. São Paulo: Ed. UNESP, 1997 [1990]. BORBA, Francisco da Silva (Coord.). Dicionário de usos do português do Brasil. São Paulo: Ática, 2002.

BORBA, Francisco da Silva (Org.). Dicionário UNESP do português contemporâneo. 1. ed. São Paulo: Ed. UNESP, 2005 [2004].

BORBA, Francisco da Silva (Org.). Grande dicionário português do Brasil. São Paulo: Ed. UNESP, no prelo.

CALDAS AULETE, F. J. Dicionário contemporâneo da lingua portuguesa. 3. ed. Lisboa: Parceria António Maria Pereira, 1948.

COSERIU, E. Teoria del lenguaje y lingüistica general. Madrid: Gredos, 1967 [1951].

FERREIRA, A. B. de H. Novo Aurélio Século XXI: o dicionário da língua portuguesa. 3. ed. Rio de Janeiro: Nova Fronteira, 1999.

HEINE, B.; CLAUDI, U.; HÜNNEMEYER, F. Grammaticalization: a conceptual framework. Chicago: The University of Chicago Press, 1991.

HOPPER, P.; TRAUGOTT, E. C. Grammaticalization. Cambridge: Cambridge University Press, 2003.

HOUAISS, A.; VILLAR, M. de S. Dicionário Houaiss da Lingua Portuguesa. Rio de Janeiro: Objetiva, 2001.

JACKENDOFF, R. Categorization, semantics and cognition. Cambridge: MIT Press, 1983 a. JACKENDOFF, R. Semantics and cognition. Cambridge: MIT Press, 1983b.

LABOV, William. The boundaries of words and their meaning. In: BAILEY, C.-J.; SHUY, R. W. (Ed.). New ways of analyzing variation in English. Washington: Georgetown University Press, 1973, p. 340-373. 
LAKOFF, G. Women, fire and other dangerous things: What categories reveal about the mind. Chicago and London: The University of Chicago Press, 1987.

LANGACKER, R. W. Foundations of cognitive grammar: Theoretical Prerequisites. v.1. Stanford, CA: Stanford University Press. Descriptive Applications. v. 2. Stanford University Press: Stanford, 1987.

NEVES, M. H. M. Guia de uso do português. Confrontando regras e usos. São Paulo: Ed. UNESP, 2003.

NEVES, M. H. M. A vertente grega da gramática tradicional: uma visão do pensamento grego sobre a linguagem. 2. ed. São Paulo: Ed. UNESP, 2005.

NEVES, M. H. M. A difusa zona adverbial. Revista Linguistica, Alfal, v. 20, p. 25-47, 2008.

NEVES, M. H. M. Ensino de lingua e vivência de linguagem: temas em confronto. São Paulo: Contexto, 2010a.

NEVES, M. H. M. Categorização e multifuncionalidade. Léxico e gramática. Revista Linguistica, Alfal, v. 23, p.59-80, 2010 b.

NEVES, M. H. M. Gramaticalização, discursividade e determinações cognitivoperceptuais. In: LIMA-HERNANDES, M. C. (org.). Gramaticalização em perspectiva: cognição, textualidade e ensino. São Paulo: Paulistana, 2010c, p. 13-26.

NEVES, M. H. M. Gramática de usos do português. 2 ed. São Paulo: Ed. UNESP, 2011a [2000].

NEVES, M. H. M. Gramática e ensino: de quando facilitar complica. In: DAHLET, V. (coord.). Ciências da linguagem e didática das linguas. São Paulo: Humanitas/ FAPESP, 2011b, p. 259-284.

NEVES, M. H. M. Linguística funcional: princípios, temas, objetos e conexões. Guavira Letras, v. 13, n. 1. Três Lagoas-MS: Programa de Pós-Graduação em Letras UFMS, p.23-38, 2011c.

NEVES, M. H. M. A necessidade da relativização de fronteiras categoriais no estudo da linguagem. A evidência das gramaticalizações em português. In: BASTOS, N. B. (org.). Língua Portuguesa: aspectos linguísticos, culturais e identitários. São Paulo: EDUC, 2012, p. 55-73.

NEVES, M. H. M. Fluidez categorial e organização textual: uma amostra de descrição gramatical funcional. In: BRAIT, B.; SOUZA-E-SILVA, C. Texto e discurso em perspectiva polifônica. São Paulo: Contexto, no prelo.

PRADO E SILVA, A. (Org.). Novo Dicionário Brasileiro Melhoramentos Ilustrado. 2 ed. São Paulo: Melhoramentos, 1964. 
ROSCH, E. Principles of categorization. In: ROSCH, E.; LLOYD, B. B. (Ed.). Cognition and categorization. Hillsdale: Lawrence Erlbaum Associates, p. 27-48, 1978.

ROSCH, E.; LLOYD, B. B. (eds.). Cognition and categorization. Hillsdale: Lawrence Erlbaum Associates, 1978.

TAYLOR, J. Grammatical categories. In: Linguistic Categorization: Prototypes in linguistic theory. 2 ed. Oxford: Oxford University Press, 1995 [1989].

TRAUGOTT, E. C.; HEINE, B. (Ed.). Approaches to grammaticalization: focus on types of grammatical markers. Amsterdam: John Benjamins, 1991.

WISHER, I. (Ed.). New Reflections on Grammaticalization. PA, USA: John Benjamins Publishing Company, 2002.

\section{Obras examinadas}

AGO Agosto. FONSECA. R. São Paulo: Cia. das Letras, 1990.

CI A cigarra - n $11-1962$

CP Ciranda de pedra. TELLES, L. F. São Paulo: Martins, 1955.

FSP Folha de S. Paulo. São Paulo, 1979, 1993; CD-ROM 1994/95.

GA Gota d'agua. HOLlANDA, C. B. Rio de Janeiro: Civ. Bras., 1980.

GCC Guerra do Cansa Cavalo. LUIS, O. São Paulo: Ed. Cons. Est. de Cultura, 1965.

I Irene. BLOCK, P. Rio de Janeiro: Ed. Talmagráfica, 1953.

MCR Maravilhas do Conto Russo. PUCHKIN, A. São Paulo: Cultrix Ltda. 1958.

MNA Maravilhas do conto norte americano. Tradu. Booker Washinton. 3. ed. São Paulo: Cultrix Ltda. 1958.

REA Realidade

RI Revista Imprensa

SVI A segunda vitória. WEST, M. Trad. Fernando de Castro Ferro. Rio de Janeiro: Record, s/d. Original de 1958.

VEJ Veja. São Paulo: Abril, 1979, 1994. Diversas edições.

VOL O Volantim - n 29-1822

DIN Diário do Nordeste 